\title{
Precipitation of $\sigma$ Phase Using General Diffusion Equation with Comparison to Vitek Diffusion Model in Dissimilar Stainless Steels
}

\author{
Chih-Chun Hsieh and Weite Wu \\ Department of Materials Science and Engineering, National Chung Hsing University, 250 Kuo-Kuang Road, Taichung 402, Taiwan
}

Correspondence should be addressed to Weite Wu, jeromehsieh@gmail.com

Received 16 August 2012; Accepted 16 October 2012

Academic Editor: Chih-Ming Chen

Copyright $\odot 2012$ C.-C. Hsieh and W. Wu. This is an open access article distributed under the Creative Commons Attribution License, which permits unrestricted use, distribution, and reproduction in any medium, provided the original work is properly cited.

This study performs a precipitation examination of the $\sigma$ phase using the general diffusion equation with comparison to the Vitek model in dissimilar stainless steels during multipass welding. Experimental results demonstrate that the diffusivities $\left(D_{\mathrm{Cr}}^{\delta}, D_{\mathrm{Ni}}^{\delta}\right.$, and $\left.D_{\mathrm{Si}}^{\delta}\right)$ of $\mathrm{Cr}, \mathrm{Ni}$, and $\mathrm{Si}$ are higher in $\delta$-ferrite than $\left(D_{\mathrm{Cr}}^{\gamma}, D_{\mathrm{Ni}}^{\gamma}\right.$, and $\left.D_{\mathrm{Si}}^{\gamma}\right)$ in the $\gamma$ phase, and that they facilitate the precipitation of the $\sigma$ phase in the third pass fusion zone. The Vitek diffusion equation can be modified as follows: $(\text { Diffusivity })_{\text {General }}=$ Modified Constant $\times(\text { Diffusivity })_{\text {Vitek }}$.

\section{Introduction}

ASSs (austenitic stainless steels) are used widely in hightemperature conditions such as energy conversion systems. For instance, to ensure economy in central power systems, sections of boilers subjected to lower temperatures are constructed from FSS (ferritic stainless steel) for economic reasons [1]. However, ASS and FSS composites have acid, alkali, and high-temperature resistances, and so have many applications in a wide variety of industries, such as chemical, oil refining, artificial fiber, food, and medicine [2].

When stainless steels are heated to temperatures between $700^{\circ} \mathrm{C}$ and $1000^{\circ} \mathrm{C}$ for prolonged periods of time, several harmful second phases, such as $\sigma, \chi$, and $\pi$, can precipitate [3-6]. While the $\sigma$ phase was first observed in the $\mathrm{Fe}-\mathrm{Cr}$ system, it has also been observed in $\mathrm{Fe}-\mathrm{Mo}, \mathrm{Fe}-\mathrm{V}$, and $\mathrm{Cr}-$ Mo-Ni alloy systems [7]. The crystallographic lattice of the $\sigma$ phase is a tetragonal structure with 30 atoms per unit cell. The $\sigma$ phase is the most important of these intermetallic phases due to its impact on the mechanical properties, corrosion resistance or weldability of stainless steels, as well as other properties [8-11].

Previous studies on the properties of stainless steels containing the $\sigma$ phase have focused on microstructural observation and the mechanical property in the fusion zone
(FZ) of similar stainless steels [12-18]. Very few researchers have discussed the precipitation of the $\sigma$ phase through the diffusion theory in the fusion zones (FZ) of dissimilar stainless steels. The precipitation behavior of the $\sigma$ phase in fusion zones during the welding process is unclear for ferritic and austenitic stainless steels. Hsieh and $\mathrm{Wu}$ [19] first reported the precipitation of the $\sigma$ phase using the Vitek diffusion model in the multipass fusion zone of dissimilar stainless steels.

Autogenous GTAW (gas tungsten arc welding) was used to manufacture dissimilar stainless steels for this present study. The precipitation behavior of the $\sigma$ phase in the multipass fusion zone of dissimilar stainless steels taking place during the multipass GTAW process has been discussed via a calculation of the general diffusion equation with comparison to the Vitek diffusion model. The objectives were to delineate the precipitation mechanism of the $\sigma$ phase in dissimilar stainless steels at various welding passes, as well as to contribute to the understanding of the precipitation behavior of the $\sigma$ phase during the multipass GTAW process in dissimilar stainless steels.

\section{Experimental Procedures}

Two types of stainless steels, namely, 304 and 430, were employed in the experiment. Both are representatives of 
TABLE 1: Chemical composition of the raw samples.

\begin{tabular}{lccccccc}
\hline \multirow{2}{*}{ Material } & \multicolumn{7}{c}{ Element (wt\%) } \\
& $\mathrm{Cr}$ & $\mathrm{Ni}$ & $\mathrm{Si}$ & $\mathrm{Mn}$ & $\mathrm{C}$ & $\mathrm{Mo}$ & $\mathrm{Fe}$ \\
\hline 304 S.S. & 19.2 & 10.9 & 1.0 & 2.0 & 0.08 & 1.22 & Bal. \\
430 S.S. & 18.3 & - & 0.75 & 1.0 & 0.12 & 1.18 & Bal. \\
\hline
\end{tabular}
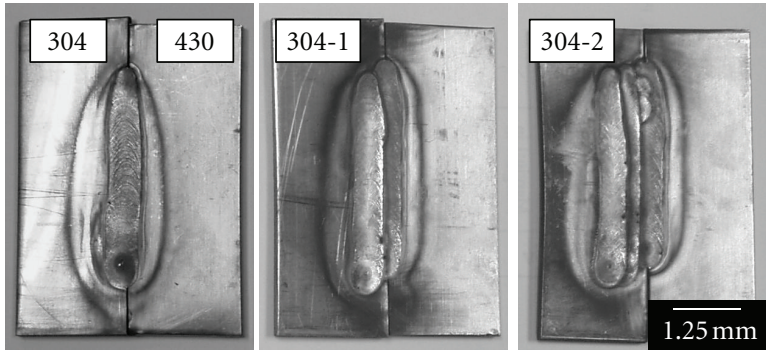

(a)

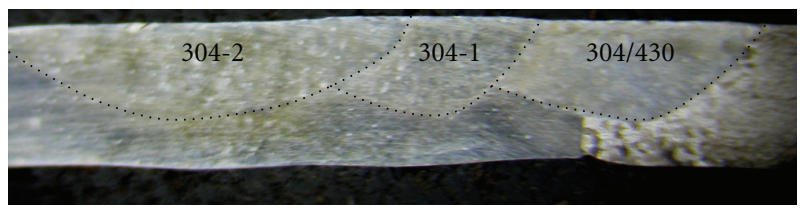

(b)

FIGURE 1: Manufacturing process of the dissimilar stainless steels. (a) Top view; (b) cross-section.

fully austenitic, that is, containing a small number of ferrite phases and fully ferritic microstructures, respectively. Their chemical compositions are listed in Table 1. The dimensions of the raw materials were $70 \mathrm{~mm} \times 25 \mathrm{~mm} \times 3 \mathrm{~mm}$.

The composites of the dissimilar stainless steels were created using an automatic GTAW process. The appearance of the weld metal from the dissimilar stainless steels is shown in Figure 1. The multipass welding (304/430, 304-1, and 3042) was performed without filler at a welding current of $100 \mathrm{~A}$ and an arc voltage of $11 \mathrm{~V}$ with a travel speed of $120 \mathrm{~mm} / \mathrm{min}$. A series of symbols for 304/430, 304-1, and 304-2 were defined as the first, second, and third pass welds, respectively.

Thin foils for observation with a transmission electron microscope (JEOL JEM-2010, HRTEM) were prepared from the third pass fusion zone. Specimens were thinned to $50 \mu \mathrm{m}$ by abrasion on SiC papers, and electropolished (Struers Tenupol-5, Twin Jet Electro-Polisher) with a twin-jet unit at $35 \mathrm{~V}$ in a mixture of $25 \%$ glycerol, $5 \%$ perchloric acid, and $75 \%$ ethanol at a temperature of $-10^{\circ} \mathrm{C}$. The method of selected area diffraction (SAD) was employed to identify the $\delta$-ferrite, $\sigma$ phase, and $\gamma$ phase. Their chemical compositions were identified using an energy dispersive spectrometer (Oxford Link ISIS, EDS).

The peak temperatures and the endothermic and exothermic peaks were examined using a differential scanning calorimeter (NETZSCH DSC $404 \mathrm{C}$ ) in order to discuss the precipitation of $\delta \rightarrow \sigma+\gamma_{2}$. The specimens were heated from $600^{\circ} \mathrm{C}$ to $1300^{\circ} \mathrm{C}$ at a heating rate of $20^{\circ} \mathrm{C} \cdot \mathrm{sec}^{-1}$. Subsequently, the diffusion parameters were calculated using
TABLE 2: TEM-EDS analysis of the third pass fusion zone (304-2).

\begin{tabular}{lccccc}
\hline \multirow{2}{*}{ Welding region } & \multirow{2}{*}{ Phase } & \multicolumn{4}{c}{ Element (wt\%) } \\
& & $\mathrm{Fe}$ & $\mathrm{Cr}$ & $\mathrm{Ni}$ & $\mathrm{Si}$ \\
\hline \multirow{2}{*}{$304-2$} & $\delta$ & 60.26 & 30.11 & 1.08 & 5.10 \\
& $\sigma$ & 55.63 & 35.58 & 2.04 & 3.32 \\
\hline
\end{tabular}

the general diffusion equation to explain the phase transformation of $\delta \rightarrow \sigma$. These diffusion parameters included diffusivity $(D)$ and the atomic jump frequencies of the solute atoms $(\Gamma)$.

\section{Results and Discussion}

3.1. TEM Identification of the $\delta$-Ferrite and $\sigma$ Phase. Figures $2(\mathrm{a})-2(\mathrm{~d})$ showed the TEM diffraction pattern of the $\delta$ ferrite and $\sigma$ phase in the third pass fusion zone (304-2). Lots of grains were found in the third pass fusion zone, as shown in Figure 2(a). Two phases can be observed clearly from a dark field image of Figure 2(b) and are identified as the $\delta$ ferrite and $\sigma$ phase using an identification of selected area diffraction, as represented in Figures 2(c) and 2(d). From the above described results, the $\sigma$ phase can precipitate in the $\delta$ ferrite after the third pass welding.

Table 2 showed the TEM-EDS result that the purpose is to analyze the compositions of $\delta$-ferrite and $\sigma$ phase in the third pass fusion zone (304-2). The $\sigma$ phase had a higher $\mathrm{Cr}$ and a lower Si contents than $\delta$-ferrite. This is because that the precipitation of $\sigma$ phase in a high $\mathrm{Cr}$ region of $\delta$-ferrite can consume Si content. Hence, the $\mathrm{Cr}$ content had a main role in forming the $\sigma$ phase, and Si had an enhanced effect on the precipitation of $\sigma$ phase.

3.2. Diffusion Calculation. The formation of a $\sigma$ phase includes temperature and elemental diffusion. Hence, this section will determine the precipitation temperature of a $\sigma$ phase using a differential scanning calorimeter (DSC) in an AISI 304 multipass welding system, as shown in Figure 3. The diagram shows two exothermic and two endothermic peaks with peak temperatures of $861^{\circ} \mathrm{C}, 934^{\circ} \mathrm{C}, 678^{\circ} \mathrm{C}$, and $893^{\circ} \mathrm{C}$, respectively. This is for the purpose of plotting the composition of the $\sigma$ phase in this study (35 wt $\% \mathrm{Cr}, 4 \mathrm{wt} \%$ $\mathrm{Ni}$ ) to the Fe-Cr-Ni phase diagram shown in Figure 4. Here, the solidification order was $L \rightarrow \delta+L \rightarrow \delta \rightarrow \delta+\gamma \rightarrow$ $\gamma+\delta+\sigma$. The above-mentioned results are marked out in Figure 4 . It was determined that the $\sigma$ phase precipitates from $400^{\circ} \mathrm{C}$ to $934^{\circ} \mathrm{C}$.

3.3. Calculation of the General Diffusion Equation. In the previous published paper [19], the diffusivities $D_{\mathrm{Cr}}^{\delta}, D_{\mathrm{Ni}}^{\delta}$, $D_{\mathrm{Ni}}^{\gamma}$, and $D_{\mathrm{Cr}}^{\gamma}$ were calculated at various peak temperatures $\left(678^{\circ} \mathrm{C}, 861^{\circ} \mathrm{C}, 893^{\circ} \mathrm{C}\right.$, and $\left.934^{\circ} \mathrm{C}\right)$, and the $\delta \rightarrow \sigma+\gamma_{2}$ eutectoid decomposition was discussed in accordance with the Vitek diffusion equation. In this section, the general diffusion equation calculation will be compared with the Vitek general equation. Its primary purpose is to examine the differences between the general diffusion and the Vitek diffusion equation. The general diffusion equation is shown 


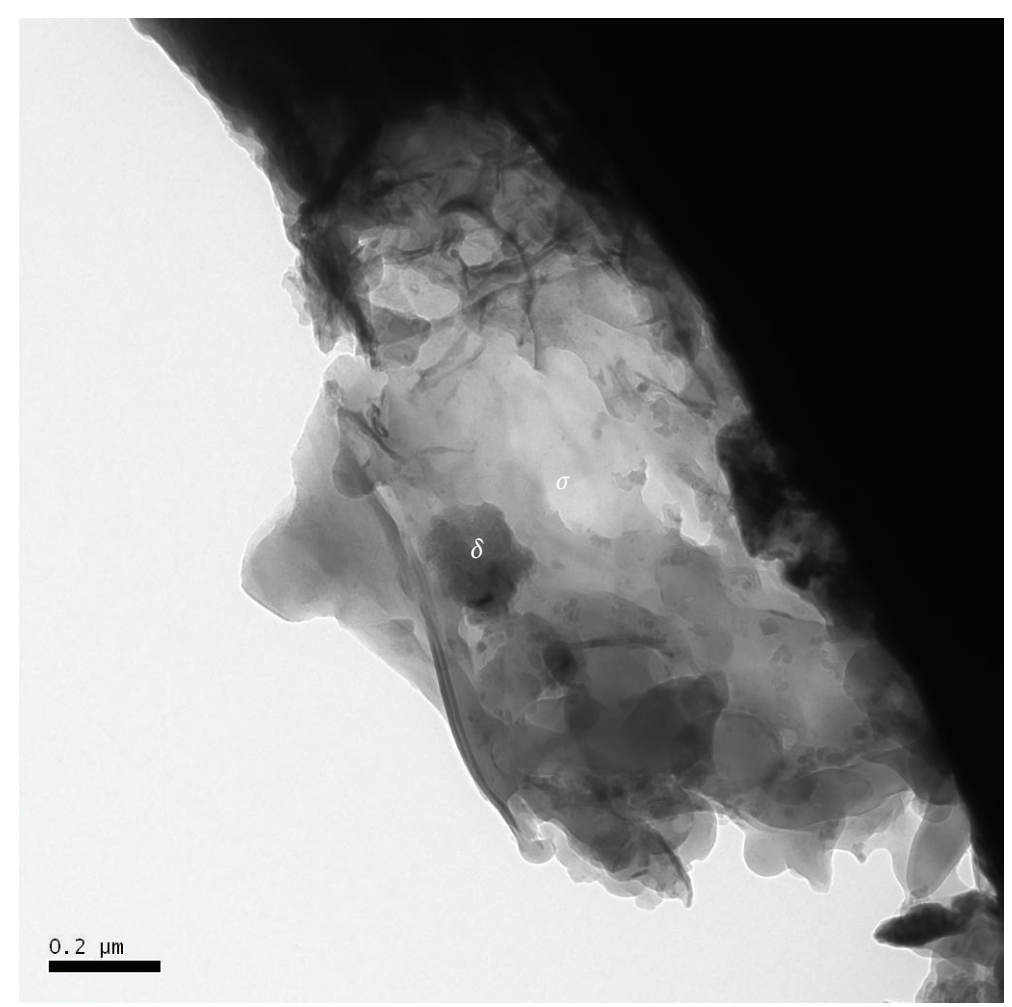

(a)

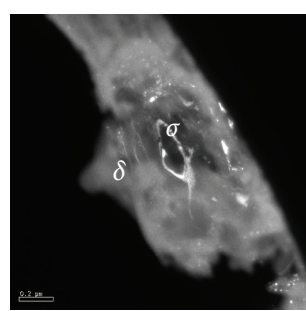

(b)

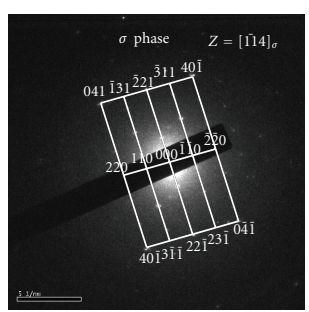

(c)

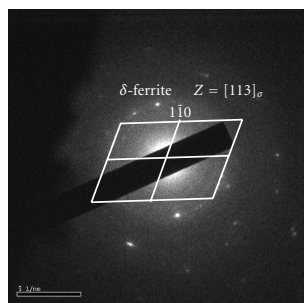

(d)

Figure 2: TEM phase identification of the third pass fusion zone. (a) Blight filed image, (b) dark field image, and (c, d) SAD pattern of the $\delta$-ferrite and $\sigma$ phase.

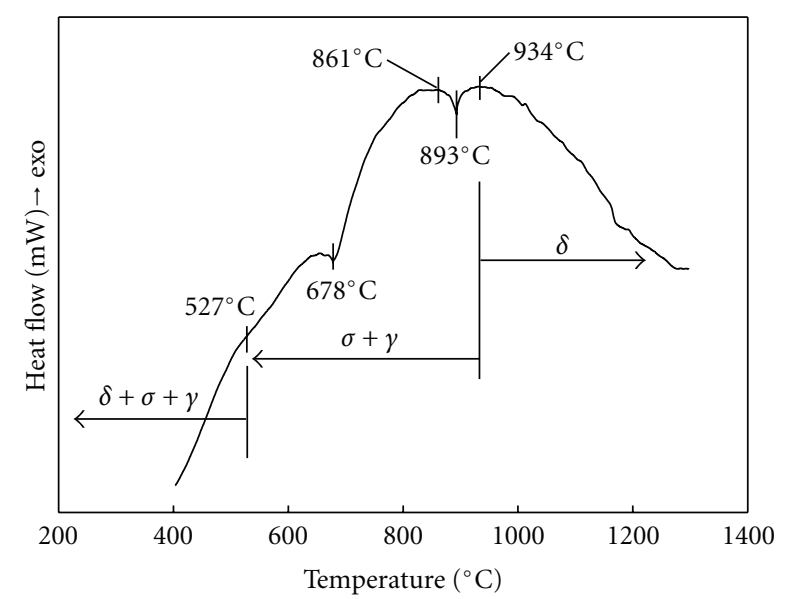

Figure 3: DSC thermal analysis of the third pass fusion zone.

in (1). Table 3 illustrates the diffusivities of various elements in stainless steel [20]. The diffusivities of $\mathrm{Cr}, \mathrm{Ni}$, and $\mathrm{Si}$ in the $\delta, \sigma$, and $\gamma$ phases at various peak temperatures for the $\delta \rightarrow \sigma+\gamma_{2}$ eutectoid decomposition were estimated through the use of the following equation and Table 3 :

$$
D=D_{0} \cdot \exp \left(\frac{-Q}{R T}\right),
$$

where $D$ is the diffusion coefficient, $\mathrm{cm}^{2} \cdot \mathrm{sec}^{-1} ; D_{0}$ is the approximate constant; $Q$ is the diffusion activation energy, $\mathrm{KJ} \cdot \mathrm{mole}^{-1} ; R$ is the gas constant $\left(=8.314 \mathrm{~J} \cdot(\text { mole } \cdot \mathrm{K})^{-1}\right) ; \mathrm{T}$ is the thermodynamic temperature, $\mathrm{K}$.

Two temperatures $\left(800^{\circ} \mathrm{C}\right.$ and $\left.1100^{\circ} \mathrm{C}\right)$ were chosen from Table 3 and substituted into (1). Subsequently, (2) and (3) were obtained. Equations (4) and (5) were derived by simplifying (2) and (3). Creating one equation from (4) and (5), (4) was divided by (5). After simplification, (6) and (7) were acquired:

$$
\begin{gathered}
D_{\mathrm{Cr}\left(800^{\circ} \mathrm{C}\right)}^{\delta}=10^{-11}=D_{0} \cdot \exp \left[\frac{-Q}{8.314(800+273)}\right], \\
D_{\mathrm{Cr}\left(1100^{\circ} \mathrm{C}\right)}^{\delta}=10^{-9}=D_{0} \cdot \exp \left[\frac{-Q}{8.314(1100+273)}\right], \\
10^{-11}=D_{0} \cdot \exp \left(-1.12 \times 10^{-4} Q\right), \\
10^{-9}=D_{0} \cdot \exp \left(-8.76 \times 10^{-5} Q\right), \\
10^{-2}=\exp \left(-1.12 \times 10^{-4} Q+8.76 \times 10^{-5} Q\right), \\
10^{-2}=\exp \left(-2.44 \times 10^{-5} \mathrm{Q}\right) .
\end{gathered}
$$

Take the natural logarithm from both sides of (7). After determining the natural logarithm, (8) and (9) were 
TABLE 3: Diffusion coefficients of elements of the $\delta$ and $\gamma$ phases in stainless steel.

\begin{tabular}{|c|c|c|c|c|c|c|c|c|c|c|}
\hline \multirow{4}{*}{ Element } & \multicolumn{10}{|c|}{ Diffusion coefficient $\left(\mathrm{cm}^{2} / \mathrm{sec}\right)$} \\
\hline & \multicolumn{5}{|c|}{$\delta(\alpha)$-iron } & \multicolumn{5}{|c|}{$\gamma$-iron } \\
\hline & \multicolumn{5}{|c|}{ Temperature $\left({ }^{\circ} \mathrm{C}\right)$} & \multicolumn{5}{|c|}{ Temperature $\left({ }^{\circ} \mathrm{C}\right)$} \\
\hline & 20 & 400 & 800 & 1100 & 1400 & 20 & 400 & 800 & 1100 & 1400 \\
\hline$\delta(\gamma)-\mathrm{Fe}$ & $10^{-46}$ & $10^{-19}$ & $10^{-12}$ & $10^{-9}$ & $10^{-7}$ & $10^{-53}$ & $10^{-22}$ & $10^{-14}$ & $10^{-11}$ & $10^{-9}$ \\
\hline $\mathrm{Al}$ & & & $10^{-11}$ & $10^{-9}$ & $10^{-7}$ & $10^{-36}$ & $10^{-15}$ & $10^{-9}$ & $10^{-8}$ & \\
\hline $\mathrm{B}$ & & & & & & $10^{-20}$ & $10^{-9}$ & $10^{-6}$ & $10^{-5}$ & \\
\hline $\mathrm{C}$ & $10^{-17}$ & $10^{-8}$ & $10^{-5}$ & $10^{-4}$ & & $10^{-27}$ & $10^{-13}$ & $10^{-8}$ & $10^{-6}$ & \\
\hline $\mathrm{Cr}$ & $10^{-42}$ & $10^{-18}$ & $10^{-11}$ & $10^{-9}$ & $10^{-7}$ & $10^{-37}$ & $10^{-18}$ & $10^{-13}$ & $10^{-11}$ & $10^{-9}$ \\
\hline $\mathrm{Co}$ & $10^{-44}$ & $10^{-19}$ & $10^{-12}$ & $10^{-10}$ & & $10^{-68}$ & $10^{-26}$ & $10^{-16}$ & $10^{-12}$ & \\
\hline $\mathrm{Cu}$ & & & $10^{-11}$ & $10^{-9}$ & & $10^{-49}$ & $10^{-20}$ & $10^{-12}$ & $10^{-10}$ & \\
\hline $\mathrm{H}$ & $10^{-5}$ & $10^{-3}$ & $10^{-3}$ & $10^{-3}$ & & $10^{-10}$ & $10^{-5}$ & $10^{-4}$ & $10^{-3}$ & \\
\hline Mn & & & & & & $10^{-53}$ & $10^{-22}$ & $10^{-14}$ & $10^{-11}$ & $10^{-9}$ \\
\hline Mo & $10^{-46}$ & $10^{-18}$ & $10^{-11}$ & $10^{-9}$ & $10^{-7}$ & $10^{-49}$ & $10^{-21}$ & $10^{-13}$ & $10^{-11}$ & $10^{-9}$ \\
\hline $\mathrm{N}$ & $10^{-17}$ & $10^{-8}$ & $10^{-6}$ & $10^{-5}$ & & $10^{-31}$ & $10^{-13}$ & $10^{-8}$ & $10^{-7}$ & \\
\hline $\mathrm{Nb}$ & & & & & & & & $10^{-13}$ & $10^{-11}$ & $10^{-9}$ \\
\hline $\mathrm{Ni}$ & $10^{-45}$ & $10^{-18}$ & $10^{-11}$ & $10^{-9}$ & & $10^{-54}$ & $10^{-23}$ & $10^{-15}$ & $10^{-11}$ & $10^{-9}$ \\
\hline $\mathrm{P}$ & $10^{-34}$ & $10^{-12}$ & $10^{-8}$ & $10^{-7}$ & $10^{-6}$ & & & $10^{-14}$ & $10^{-9}$ & $10^{-8}$ \\
\hline$S$ & $10^{-34}$ & $10^{-12}$ & $10^{-8}$ & $10^{-7}$ & $10^{-6}$ & & & $10^{-14}$ & $10^{-9}$ & $10^{-8}$ \\
\hline $\mathrm{Si}$ & $10^{-50}$ & $10^{-21}$ & $10^{-13}$ & $10^{-11}$ & $10^{-7}$ & $10^{-48}$ & $10^{-20}$ & $10^{-13}$ & $10^{-12}$ & $10^{-9}$ \\
\hline $\mathrm{Ti}$ & $10^{-47}$ & $10^{-19}$ & $10^{-12}$ & $10^{-9}$ & $10^{-7}$ & $10^{-49}$ & $10^{-21}$ & $10^{-13}$ & $10^{-11}$ & $10^{-9}$ \\
\hline $\mathrm{V}$ & & & $10^{-12}$ & $10^{-9}$ & $10^{-7}$ & & & $10^{-14}$ & $10^{-11}$ & $10^{-9}$ \\
\hline $\mathrm{W}$ & $10^{-60}$ & $10^{-26}$ & $10^{-17}$ & $10^{-10}$ & & $10^{-68}$ & $10^{-30}$ & $10^{-20}$ & $10^{-16}$ & \\
\hline
\end{tabular}

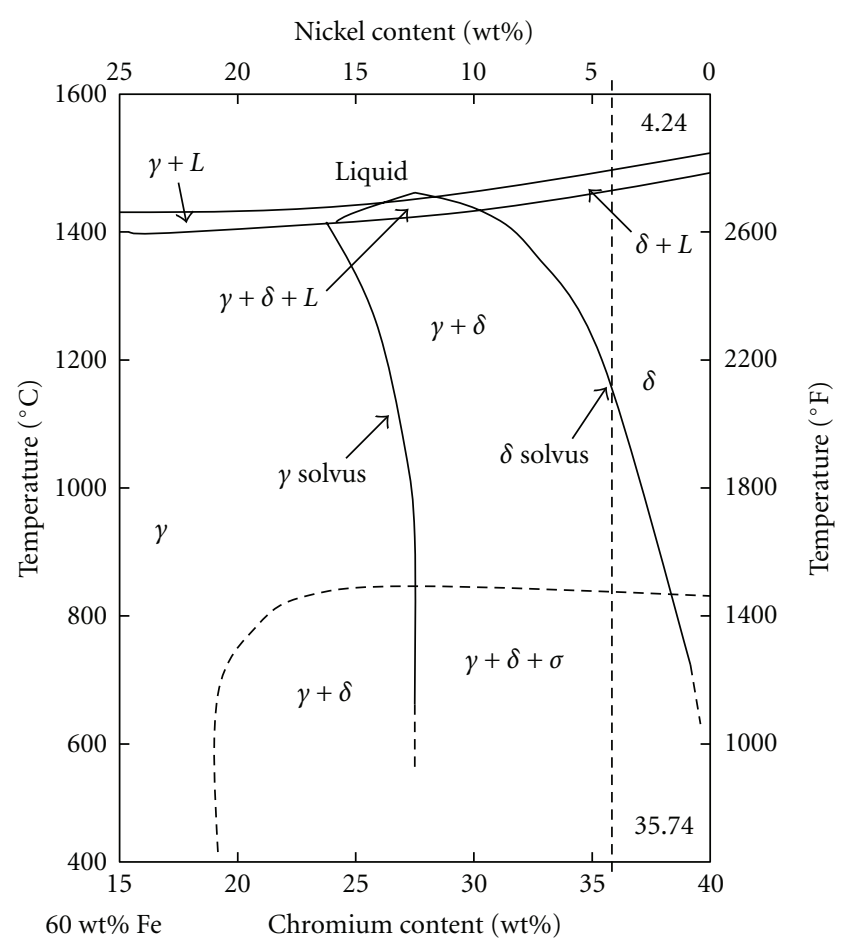

Figure 4: The Fe-Cr-Ni phase diagram $(60 \% \mathrm{Cr})$. obtained. By calculating (9), the diffusion activation energy was calculated:

$$
\begin{gathered}
\ln \left(10^{-2}\right)=\ln \left[\exp \left(-2.44 \times 10^{-5} Q\right)\right], \\
-4.605=-2.44 \times 10^{-5} Q
\end{gathered}
$$

then $Q=188729 \mathrm{KJ} \cdot \mathrm{mole}^{-1}$.

The $Q=188729 \mathrm{KJ} \cdot \mathrm{mole}^{-1}$ and $678^{\circ} \mathrm{C}$ were substituted into (3) and (1), respectively. Hence, (10) and (11) were obtained.

One equation was created from (10) and (11) and sorted simultaneously, as shown in (12)-(14). Finally, the diffusivity of $\mathrm{Cr}$ in $\delta$-ferrite at $678^{\circ} \mathrm{C}\left(D_{\mathrm{Cr}\left(678^{\circ} \mathrm{C}\right)}^{\delta}\right)$ can be calculated.

In accordance with the above calculated method, a series of diffusivities $\left(D_{\mathrm{Cr}}^{\delta}, D_{\mathrm{Ni}}^{\delta}, D_{\mathrm{Ni}}^{\gamma}, D_{\mathrm{Cr}}^{\gamma}, D_{\mathrm{Si}}^{\delta}\right.$, and $\left.D_{\mathrm{Si}}^{\gamma}\right)$ in the $\delta$ and $\gamma$ phases at different peak temperatures $\left(861^{\circ} \mathrm{C}, 893^{\circ} \mathrm{C}\right.$, and $\left.934^{\circ} \mathrm{C}\right)$. The calculated results are listed in Table 4. $D_{\mathrm{Cr}}^{\delta}=D_{\mathrm{Ni}}^{\delta}$, indicates that it held the same diffusivity $(6.58 \times$ $10^{-13} \mathrm{~cm}^{2} \cdot \mathrm{sec}^{-1}$ ) of $\mathrm{Cr}$ and $\mathrm{Ni}$ in $\delta$-ferrite during the $\delta \rightarrow$ $\sigma+\gamma_{2}$ eutectoid decomposition. Therefore, the $\mathrm{Cr}$ and $\mathrm{Ni}$ were easier to diffuse in the $\delta$-ferrite than in the $\gamma$-phase. This can be attributed to higher $\left(D_{\mathrm{Cr}}^{\delta}\right.$ and $\left.D_{\mathrm{Ni}}^{\delta}\right)$ and lower diffusivities $\left(D_{\mathrm{Ni}}^{\gamma}\right)$. Consequently, the $\sigma$ phase and secondary austenite $\left(\gamma_{2}\right)$ were precipitated in the $\delta$-ferrite particles in 
TAble 4: Diffusivities of the elements of $\mathrm{Cr}, \mathrm{Ni}$, and $\mathrm{Si}$ in $\delta$-ferrite and $\gamma$-austenite at various peak temperatures in accordance with the general diffusion equation $\left(D_{\text {general }}\right)$.

\begin{tabular}{|c|c|c|c|c|c|c|}
\hline \multirow{2}{*}{ Temperature $\left({ }^{\circ} \mathrm{C}\right)$} & \multicolumn{6}{|c|}{ Diffusivity $\left(\mathrm{cm}^{2} / \mathrm{sec}\right)$} \\
\hline & $D_{\mathrm{Cr}}^{\delta}$ & $D_{\mathrm{Ni}}^{\gamma}$ & $D_{\mathrm{Ni}}^{\delta}$ & $D_{\mathrm{Cr}}^{\gamma}$ & $D_{\mathrm{Si}}^{\delta}$ & $D_{\mathrm{Si}}^{\gamma}$ \\
\hline 678 & $6.58 \times 10^{-13}$ & $4.38 \times 10^{-18}$ & $6.58 \times 10^{-13}$ & $6.58 \times 10^{-15}$ & $6.39 \times 10^{-15}$ & $2.56 \times 10^{-14}$ \\
\hline 861 & $3.09 \times 10^{-11}$ & $9.26 \times 10^{-15}$ & $3.09 \times 10^{-11}$ & $3.09 \times 10^{-13}$ & $3.13 \times 10^{-13}$ & $1.75 \times 10^{-13}$ \\
\hline 893 & $5.36 \times 10^{-11}$ & $3.33 \times 10^{-14}$ & $5.36 \times 10^{-11}$ & $5.37 \times 10^{-13}$ & $5.46 \times 10^{-13}$ & $2.32 \times 10^{-13}$ \\
\hline 934 & $1.04 \times 10^{-10}$ & $1.08 \times 10^{-13}$ & $1.04 \times 10^{-10}$ & $1.04 \times 10^{-12}$ & $1.08 \times 10^{-12}$ & $3.23 \times 10^{-13}$ \\
\hline
\end{tabular}

TABLE 5: Jump frequencies of the solute atoms of $\mathrm{Cr}, \mathrm{Ni}$, and $\mathrm{Si}$ in $\delta$ and $\gamma$ at various peak temperatures.

\begin{tabular}{|c|c|c|c|c|c|c|}
\hline \multirow{2}{*}{ Temperature $\left({ }^{\circ} \mathrm{C}\right)$} & \multicolumn{6}{|c|}{ Jump frequencies of solute atoms $\left(\mathrm{sec}^{-1}\right)$} \\
\hline & $\Gamma_{\mathrm{Cr}}^{\delta}$ & $\Gamma_{\mathrm{Ni}}^{y}$ & $\Gamma_{\mathrm{Ni}}^{\delta}$ & $\Gamma_{\mathrm{Cr}}^{\gamma}$ & $\Gamma_{\mathrm{Si}}^{\delta}$ & $\Gamma_{\mathrm{Si}}^{y}$ \\
\hline 678 & 6370 & 0.04 & 6370 & 61 & 62 & 238 \\
\hline 861 & 299000 & 90 & 299000 & 2877 & 3040 & 1629 \\
\hline 893 & 518000 & 310 & 518000 & 5001 & 5307 & 2165 \\
\hline 934 & 1012317 & 1004 & 1012317 & 9695 & 10400 & 3003 \\
\hline
\end{tabular}

the third pass fusion zone. However, there is no prediction for the diffusivity of Si in the $\delta$-ferrite and $\gamma$ phase $\left(D_{\mathrm{Si}}^{\delta}\right.$ and $D_{\mathrm{Si}}^{\gamma}$ ) in regard to the Vitek diffusion equation. The empirical formula for Si in the $\delta$ and $\gamma$ phases was derived from the general diffusion equation, as illustrated in (15) and (16). Table 4 shows the $D_{\mathrm{Si}}^{\delta}>D_{\mathrm{Si}}^{\gamma}$ indicating that Si had a higher diffusion rate in $\delta$-ferrite than in the $\gamma$-phase. However, the Si can promote $\delta \rightarrow \sigma+\gamma_{2}$ eutectoid decomposition from the above-described result. This is the primary reason that precipitation of the $\sigma$ phase occurs through a Fe-Cr-Si-rich intermetallic compound in the third pass fusion zone of this study:

$$
\begin{gathered}
10^{-11}=D_{0} \cdot \exp \left[\frac{-188729}{8.314(800+273)}\right], \\
D_{\mathrm{Cr}\left(678^{\circ} \mathrm{C}\right)}^{\delta}=D_{0} \cdot \exp \left[\frac{-188729}{8.314(677.9+273)}\right], \\
\frac{10^{-11}}{D_{\mathrm{Cr}\left(678^{\circ} \mathrm{C}\right)}^{\delta}}=\exp (-21.15+23.87), \\
D_{\mathrm{Cr}\left(678^{\circ} \mathrm{C}\right)}^{\delta}=\frac{10^{-11}}{\exp (-21.15+23.87)} \\
D_{\mathrm{Cr}\left(678^{\circ} \mathrm{C}\right)}^{\delta}=\frac{10^{-11}}{15.18},
\end{gathered}
$$

then $D_{\mathrm{Cr}\left(678^{\circ} \mathrm{C}\right)}^{\delta}=6.58 \times 10^{-13} \mathrm{~cm}^{2} \cdot \mathrm{sec}^{-1}$,

$$
\begin{aligned}
& D_{\mathrm{Si}}^{\delta}=\exp \left(-\frac{22700}{T}\right), \\
& D_{\mathrm{Si}}^{\gamma}=\exp \left(-\frac{11337}{T}\right) .
\end{aligned}
$$

3.4. The Jump Frequencies of the $\mathrm{Cr}, \mathrm{Ni}$, and Si Atoms in $\delta$ and $\gamma$ Phases. Atom jump frequency $(\Gamma)$ can be calculated using the above-mentioned calculation of diffusivities. This section will explain the mechanisms of eutectoid decomposition from an atom jump perspective. Atom jump frequency can be calculated as shown in the following equation:

$$
\Gamma=\frac{6 D}{\lambda^{2}},
$$

where $\Gamma$ is the jump frequency of solute atom $\left(\mathrm{sec}^{-1}\right), D$ is the diffusion coefficient $\left(\mathrm{cm}^{2} \cdot \mathrm{sec}^{-1}\right)$, and $\lambda$ represents space between the two atoms ( $\mathrm{nm}$ ).

Because the atom spacing of the $\delta$-ferrite and $\gamma$ phase is $\sqrt{3} a / 2$ and $\sqrt{2} a / 2$, respectively, it is understood that the lattice constants of the $\delta$-ferrite and $\gamma$ phases are about $2.87 \mathrm{~nm}$ and $0.359 \mathrm{~nm}$. Then, the values of diffusivities from Table 5 were substituted into (17), and a series of the jump frequencies were obtained, as shown in Table 4. This Table shows $\Gamma_{\mathrm{Cr}}^{\delta}=\Gamma_{\mathrm{Ni}}^{\delta}$ in the third pass fusion zone. This means that the solute atoms of $\mathrm{Cr}$ and $\mathrm{Ni}$ had a higher atom jump frequency with a temperature range of $678^{\circ} \mathrm{C}, 861^{\circ} \mathrm{C}, 893^{\circ} \mathrm{C}$, and $934^{\circ} \mathrm{C}$ in the eutectoid decomposition of $\delta \rightarrow \sigma+\gamma_{2}$, as shown in Figure 5. This tendency is in agreement with previous results $\left(D_{\mathrm{Cr}}^{\delta}=D_{\mathrm{Ni}}^{\delta}\right)$. Especially notable at $934^{\circ} \mathrm{C}$, the jump frequencies of $\mathrm{Cr}$ and $\mathrm{Ni}$ solute atoms were about $10^{7}$ times per second in $\delta$-ferrite in the third pass fusion zone. Conversely, the jump frequency of the Ni solute atom in the $\gamma$ phase was very small (just 1004 times) at $934^{\circ} \mathrm{C}$, as shown in Figure 6. Hence, the $\sigma$ phase and secondary austenite $\left(\gamma_{2}\right)$ formed easily in $\delta$-ferrite. Furthermore, the jump frequency of the Si solute atom in $\delta$-ferrite $\left(\Gamma_{\mathrm{Si}}^{\delta}\right)$ was higher than that of $\mathrm{Cr}$ and $\mathrm{Ni}$ in $\delta$-ferrite $\left(\Gamma_{\mathrm{Cr}}^{\delta}\right.$ and $\left.\Gamma_{\mathrm{Ni}}^{\delta}\right)$. As shown in Figure 7, the diffusivity of the Si solute atom increased with an increase in the jump frequency of the $\mathrm{Si}$ solute at various peak temperatures. Hence, the Si can be understood to accelerate the eutectoid decomposition of $\delta \rightarrow \sigma+\gamma_{2}$.

3.5. Modified Vitek Diffusion Equation. As previous Hsieh and Wu's study in Table 6 [19], the difference in diffusivities between the $D_{\mathrm{Cr}}^{\delta}$ and $D_{\mathrm{Ni}}^{\delta}$ was very small according to the Vitek model calculation. This is despite the fact that 
Table 6: Diffusivities of the $\mathrm{Cr}$ and $\mathrm{Ni}$ in $\delta$-ferrite and $\gamma$-austenite at various peak temperatures in accordance with the Vitek model.

\begin{tabular}{lcccc}
\hline Peak temperature $\left({ }^{\circ} \mathrm{C}\right)$ & \multicolumn{2}{c}{ Diffusivity $\left(\mathrm{cm}^{2} \cdot \mathrm{sec}^{-1}\right)$} & $D_{\mathrm{Ni}}^{\delta}$ & $D_{\mathrm{Cr}}^{\gamma}$ \\
\hline 678 & $D_{\mathrm{Cr}}^{\delta}$ & $D_{\mathrm{Ni}}$ & $1.00 \times 10^{-13}$ & $3.78 \times 10^{-16}$ \\
861 & $1.31 \times 10^{-13}$ & $4.11 \times 10^{-16} \times 10^{-14}$ & $1.34 \times 10^{-11}$ & $1.60 \times 10^{-13}$ \\
893 & $1.74 \times 10^{-11}$ & $1.13 \times 10^{-13}$ & $2.71 \times 10^{-11}$ & $3.84 \times 10^{-13}$ \\
934 & $3.52 \times 10^{-11}$ & $3.18 \times 10^{-13}$ & $6.26 \times 10^{-11}$ & $1.08 \times 10^{-12}$ \\
\hline
\end{tabular}

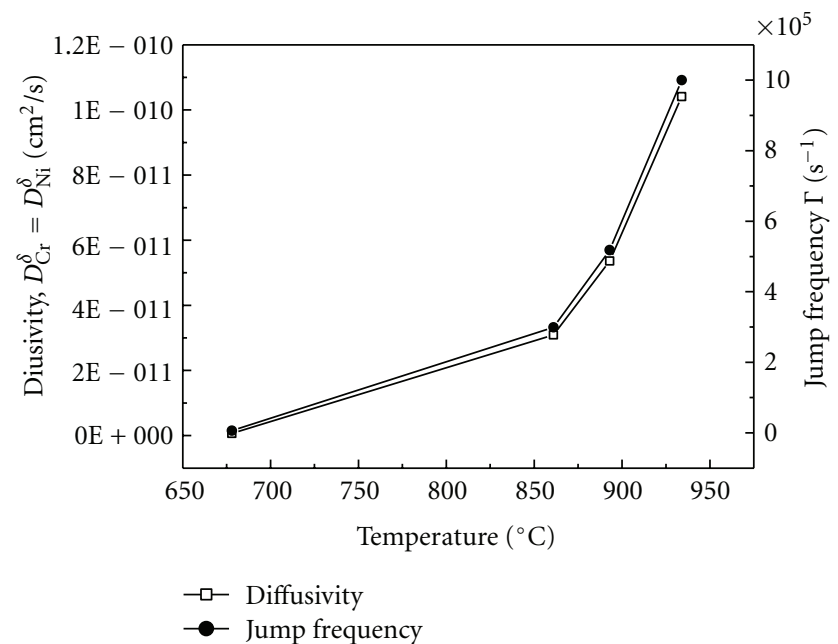

Figure 5: The diffusivities of $D_{\mathrm{Cr}}^{\delta}$ and $D_{\mathrm{Ni}}^{\delta}$ and the jump frequencies at various peak temperatures.

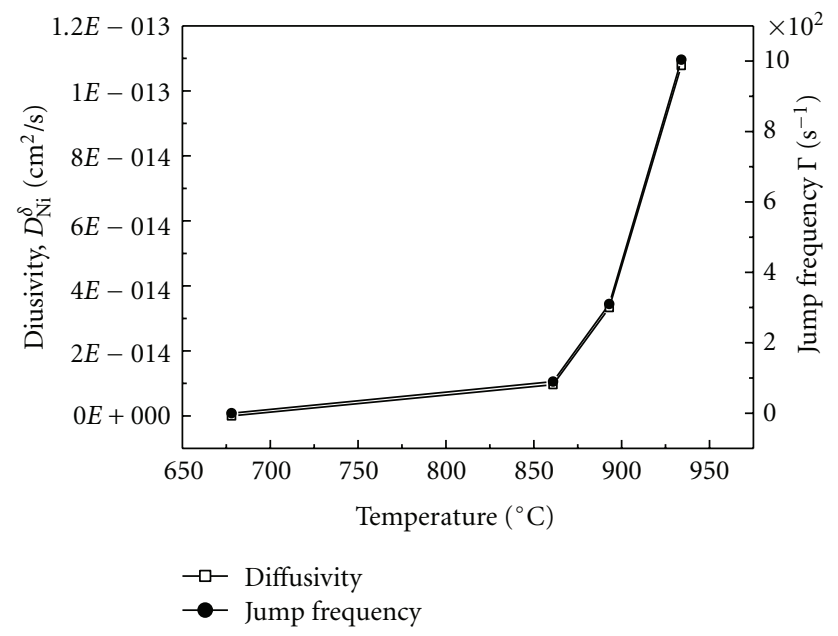

FIGURE 6: The diffusivity of $D_{\mathrm{Ni}}^{\gamma}$ and the jump frequencies at various peak temperatures.

the order of the $D_{\mathrm{Cr}}^{\delta}$ is equivalent to the $D_{\mathrm{Ni}}^{\delta}$. Generally speaking, the general diffusion equation is more precise than other diffusion empirical equations. For this study, the Vitek diffusion equation was modified and its accuracy improved, as indicated in (18). The modifications are listed in Table 7 where it is shown that the modified coefficient had a greater at $678^{\circ} \mathrm{C}$ than other peak temperatures. In total, the difference between the general diffusion equation and

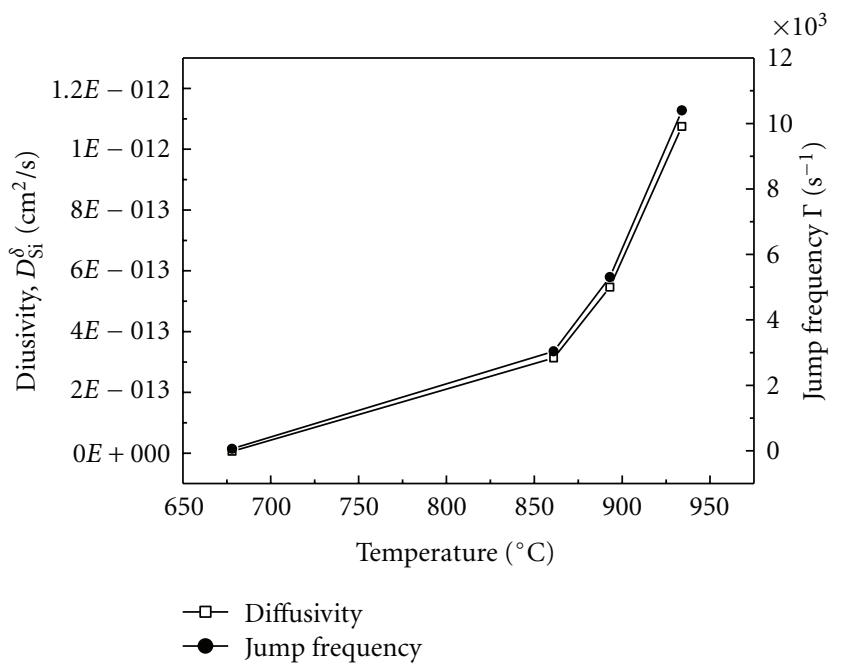

FIGURE 7: The diffusivity of $D_{\mathrm{Si}}^{\delta}$ and the jump frequencies at various peak temperatures.

TABle 7: Modified diffusion equation at various peak temperatures.

\begin{tabular}{lcccc}
\hline \multirow{2}{*}{ Temperature $\left({ }^{\circ} \mathrm{C}\right)$} & \multicolumn{4}{c}{ Coefficient } \\
& $C_{\mathrm{Cr}}^{\delta}$ & $C_{\mathrm{Ni}}^{\gamma}$ & $C_{\mathrm{Ni}}^{\delta}$ & $C_{\mathrm{Cr}}^{\gamma}$ \\
\hline 678 & 5.02 & 0.33 & 6.58 & 17.4 \\
861 & 1.77 & 0.19 & 2.30 & 1.93 \\
893 & 1.52 & 0.29 & 1.98 & 1.39 \\
934 & 1.27 & 0.34 & 1.66 & 0.96 \\
\hline$*(D)_{\text {General }}=(C) \times(D)_{\text {Vitek }}$. & & &
\end{tabular}

the Vitek diffusion equation did not exceed $10^{2}$. The Vitek model showed a quite accuracy for predicting the diffusion coefficient; however, the modified Vitek model can increase its precision:

$$
(D)_{\text {General }}=(C) \times(D)_{\text {Vitek }} \text {, }
$$

where $(D)_{\text {General }}$ is a diffusivity of general diffusion equation calculation $\left(\mathrm{cm}^{2} \cdot \mathrm{sec}^{-1}\right),(C)$ is a modified coefficient, and $(D)_{\text {Vitek }}$ is a diffusivity of Vitek diffusion model calculation $\left(\mathrm{cm}^{2} \cdot \mathrm{sec}^{-1}\right)$.

\section{Conclusions}

In this study, a new method for the examination of the $\delta \rightarrow$ $\sigma+\gamma_{2}$ phase transformation within multipass fusion zones was investigated. The new method employed the general 
diffusion equation with comparison to the Vitek diffusion model during multipass dissimilar stainless steel welding. The significant results were as follows.

(1) The precipitation of the $\sigma$ phase in the $\delta$-ferrite was observed using TEM-SAD and TEM-EDS after the multipass welding.

(2) The diffusion coefficients of Si in $\delta$-ferrite and $\gamma$ austenite were predicted using the general diffusion equation with comparison to the Vitek diffusion model.

(3) The Vitek diffusion equation was modified as in the following equation: $(D)_{\text {General }}=(C) \times(D)_{\text {Vitek }}$ in the multipass fusion zone.

\section{Acknowledgment}

The authors are obligated to thank the National Science Council of Taiwan, for their financial support under Projects no. NSC 101-2811-E-005-001 and NSC 101-2623-E-005002-ET.

\section{References}

[1] S. Missori and C. Koerber, "Laser beam welding of austeniticrerritic transition joints," Welding Journal, vol. 76, no. 12, pp. 125S-134S, 1997.

[2] B. Sun, Y. J. Li, Q. Chi, and X. S. Zhang, "Analysis of the microstructure in the weld zone of $0 \mathrm{Cr}_{18} \mathrm{Mo}_{2}$ and $1 \mathrm{Cr}_{18} \mathrm{Ni}_{9} \mathrm{Ti}$ dissimilar stainless steel," Chemical Engineering and Machinery, vol. 31, no. 1, pp. 17-23, 2004.

[3] P. Michael, S. Oliver, and G. Thomas, "Effect of intermetallic precipitations on the properties of duplex stainless steel," Materials Characterization, vol. 58, pp. 65-71, 2007.

[4] R. F. Steigerwald, "Effects of metallic second phases in stainless steels," Corrosion, vol. 33, no. 9, pp. 338-343, 1977.

[5] H. Kiesheyer and H. Brandis, "Investigation of phase equilibria in the ternary system Fe-Cr-Mo in the solid state," Zeitschrift fuer Metallkunde, vol. 67, no. 4, pp. 258-263, 1976.

[6] C. J. Park, M. K. Ahn, and H. S. Kwon, "Influences of Mo substitution by $\mathrm{W}$ on the precipitation kinetics of secondary phases and the associated localized corrosion and embrittlement in 29\% Cr ferritic stainless steels," Materials Science and Engineering A, vol. 418, pp. 211-217, 2006.

[7] M. Raghavan, G. A. Mueller, G. A. Vaughn, and S. Floreen, "Determination of isothermal sections of nickel rich portion of Ni-Cr-Mo system by analytical electron microscopy," Metallurgical Transactions A, vol. 15, no. 5, pp. 783-792, 1984.

[8] L. Karlsson, L. Ryen, and S. Pak, "Precipitation of intermetallic phases in $22 \% \mathrm{Cr}$ duplex stainless weld metals," Welding Journal, vol. 74, pp. 28S-40S, 1995.

[9] T. H. Chen, K. L. Weng, and J. R. Yang, "The effect of hightemperature exposure on the microstructural stability and toughness property in a 2205 duplex stainless steel," Materials Science and Engineering A, vol. 338, no. 1-2, pp. 259-270, 2002.

[10] J. O. Nilsson, P. Kangas, and T. Karlsson, "Mechanical properties, microstructural stability and kinetics of $\sigma$-phase formation in $29 \mathrm{Cr}-6 \mathrm{Ni}-2 \mathrm{Mo}-0.38 \mathrm{~N}$ superduplex stainless steel," Metallurgical and Materials Transactions A, vol. 31, pp. 35-45, 2000.
[11] L. Jinchun, W. Tuyan, and R. Yves:, " $\delta$ phase precipitation and its effect on the mechanical properties of a super duplex stainless steel," Materials Science and Engineering A, vol. 174, pp. 149-156, 1994.

[12] A. Turnbull, P. E. Francis, M. P. Ryan, L. P. Orkney, A. J. Griffiths, and B. Hawkins, "A novel approach to characterizing the corrosion resistance of super duplex stainless steel welds," Corrosion, vol. 58, no. 12, pp. 1039-1048, 2002.

[13] D. Y. Lin, G. L. Liu, T. C. Chang, and H. C. Hsieh, "Microstructure development in $24 \mathrm{Cr}-14 \mathrm{Ni}-2 \mathrm{Mn}$ stainless steel after aging under various nitrogen/air ratios," Journal of Alloys and Compounds, vol. 377, pp. 150-154, 2004.

[14] C. C. Hsieh, D. Y. Lin, and W. Wu, "Precipitation behavior of $\sigma$ phase in $19 \mathrm{Cr}-9 \mathrm{Ni}-2 \mathrm{Mn}$ and $18 \mathrm{Cr}-0.75 \mathrm{Si}$ stainless steels hot-rolled at $800^{\circ} \mathrm{C}$ with various reduction ratios," Materials Science and Engineering A, vol. 467, pp. 181-189, 2007.

[15] C. C. Hsieh, T. C. Chang, D. Y. Lin, and M. C. Chen, "Dispersion strengthening behavior of $\sigma$ phase in 304 modified stainless steels during $1073 \mathrm{~K}$ hot rolling," Metals and Materials International, vol. 13, pp. 359-363, 2007.

[16] C. C. Hsieh, D. Y. Lin, and W. Wu, "Precipitation behavior of $\sigma$ phase in fusion zone of dissimilar stainless steel welds during multi-pass GTAW process," Metals and Materials International, vol. 13, pp. 411-416, 2007.

[17] C. C. Hsieh, D. Y. Lin, and T. C. Chang, "Microstructural evolution during the $\delta / \sigma / \gamma$ phase transformation of the SUS 309LSi stainless steel after aging under various nitrogen atmospheric ratios," Materials Science and Engineering A, vol. 475, no. 1-2, pp. 128-135, 2008.

[18] C. C. Hsieh, X. Guo, and W. Wu, "Dendrite evolution of delta $(\delta)$ ferrite and precipitation behavior of sigma $(\sigma)$ phase during multipass dissimilar stainless steels welding," Metals and Materials International, vol. 16, pp. 349-356, 2010.

[19] C. C. Hsieh and W. Wu, "Discussing the precipitation behavior of $\sigma$ phase using diffusion equation and thermodynamic simulation in dissimilar stainless steels," Journal of Alloys and Compounds, vol. 506, pp. 820-825, 2010.

[20] E. Folkhard, G. Rabensteiner, E. Perteneder, H. Schabereiter, and J. Tösch, Welding Metallurgy of Stainless Steels, Springer, New York, NY, USA, 2004. 

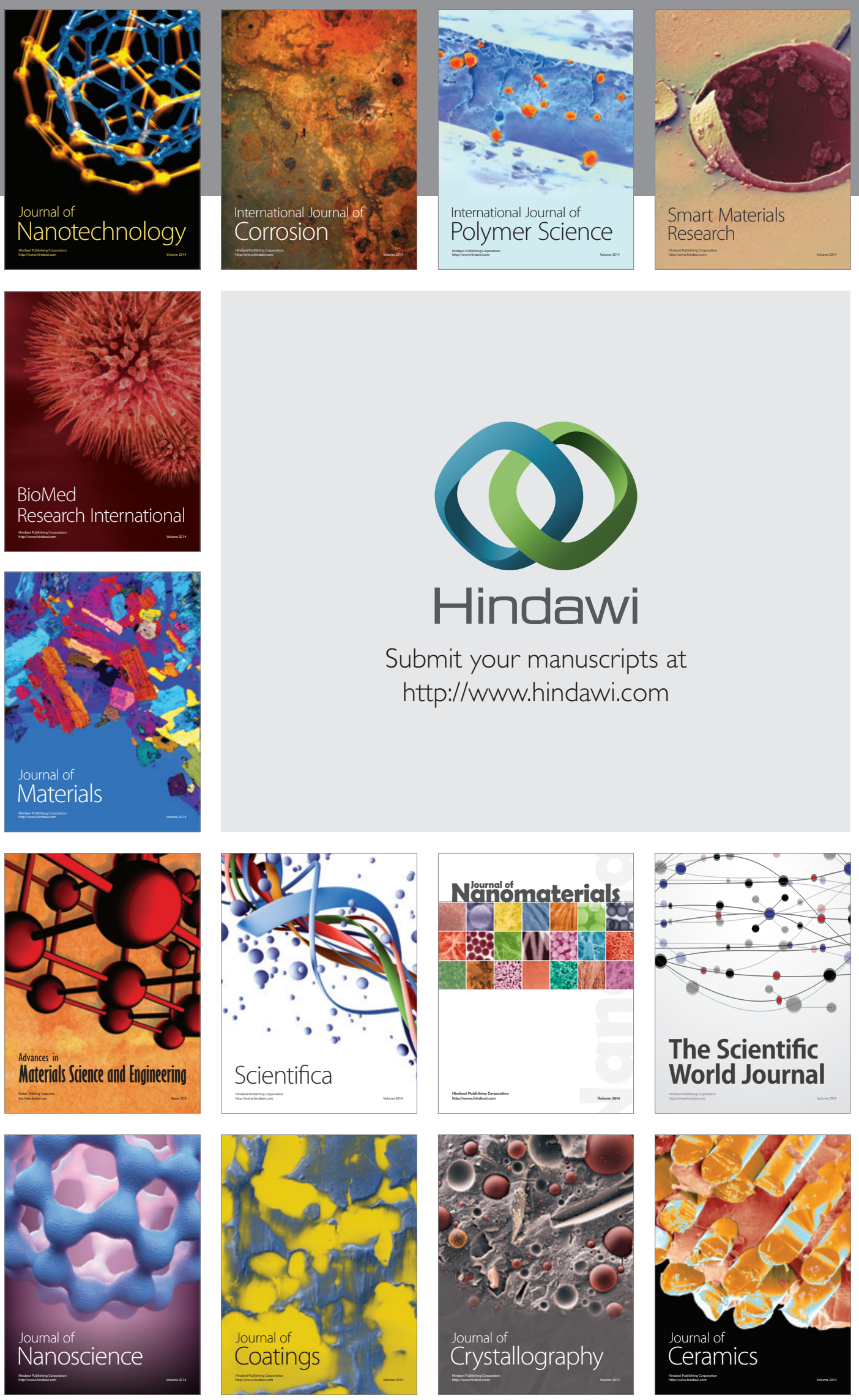

The Scientific World Journal

Submit your manuscripts at

http://www.hindawi.com

\section{World Journal}

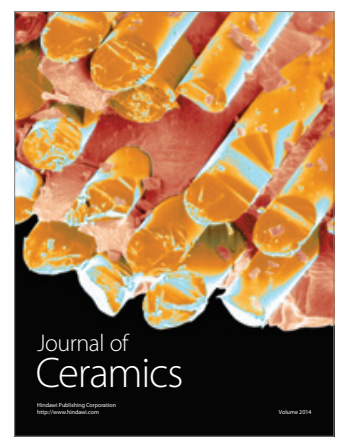

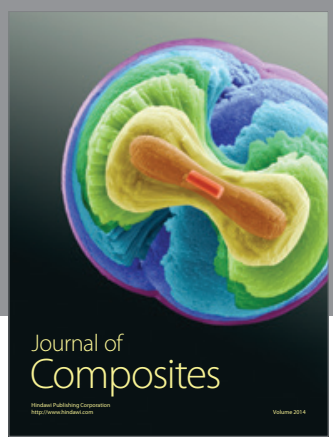
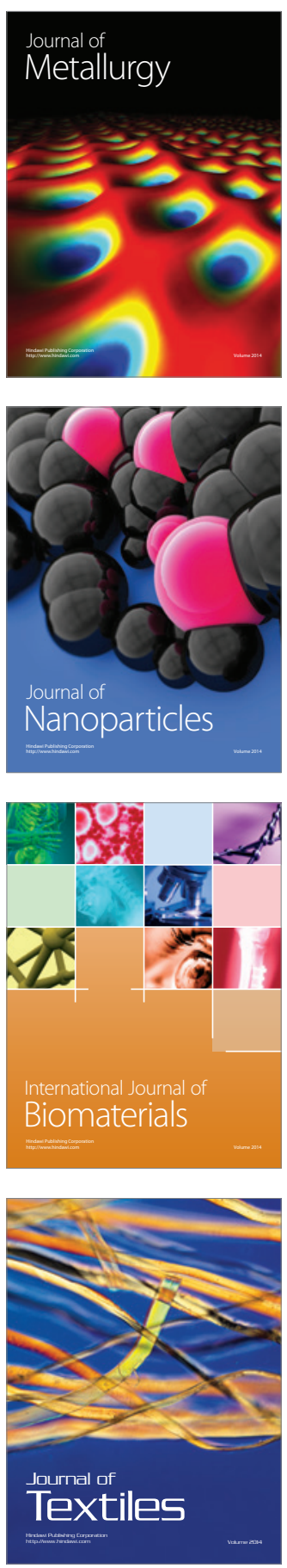